\title{
Enhancement of teprenone isomer separation by subcritical fluid chromatography using porous graphitic carbon column
}

\author{
Chang Hwa Jin ${ }^{1,2 \dagger}$, Han Young Eom ${ }^{3 \dagger}$, Seong Jun Bae ${ }^{2}$, Hyun-Deok $\mathrm{Cho}^{3}$ and Sang Beom Han ${ }^{{ }^{*}}$
}

\begin{abstract}
Teprenone is a therapeutic anti-ulcer agent developed in Japan. As described in the Japanese Pharmacopoeia (JP) 17th Edition, gas chromatography/hydrogen flame ionization detection (GC/FID) and high-performance liquid chromatography/ultraviolet detection (HPLC/UV) have been used for the assay of active pharmaceutical ingredients (APIs) and teprenone capsules, respectively. The critical aspect of the assay is a separation of the structural isomers (mono-cis and all-trans) of teprenone. Herein, we propose an improved quantitative method for the quality control of teprenone in APIs and capsules via subcritical fluid chromatography/photo diode array detection (SubFC/PDA) using a porous graphitic carbon column. SubFC conditions, i.e., type and content of the organic modifier in the mobile phase, column temperature, injection volume, and flow rate, were optimized. The developed SubFC/PDA method was validated according to ICH guidelines Q2(R1) in terms of accuracy, precision (repeatability and intermediate precision), specificity, linearity, quantification range, robustness, and stability. Comparison of SubFC/ PDA method with the GC/FID or HPLC/UV method (described in JP) revealed that the SubFC/PDA method gave better resolution and run time than the JP methods. The developed SubFC/PDA method is expected to be useful for pharmaceutical analysis or quality control of teprenone isomers.
\end{abstract}

Keywords: Teprenone, Subcritical fluid chromatography, Mono-cis, All-trans, Graphitic carbon column, Japanese Pharmacopoeia

\section{Introduction}

Teprenone, an acyclic polyisoprenoid compound, and is sometimes called tetraprenylacetone or geranylgeranylacetone (Murakami et al. 1981), is a therapeutic agent developed in Japan for the treatment of gastric ulcers and gastritis. It protects gastric mucosal lesions by increasing the amount of gastric mucus in the injured area of the patient's stomach without affecting physiological functions,

\footnotetext{
* Correspondence: hansb@cau.ac.kr

${ }^{+}$Chang Hwa Jin and Han Young Eom contributed equally to this work. 'Department of Pharmaceutical Analysis, College of Pharmacy, Chung-Ang University, 84 Heukseok-ro, Dongjak-gu, Seoul 06974, Republic of Korea
} Full list of author information is available at the end of the article such as gastric juice secretion or stomach exercise. This involves increasing the number of important macromolecule proteins and phospholipids as a defense factor in gastric mucosa and gastric mucus by enhancing the biosynthesis of glycolipids in microsomes of gastric mucosal cells. Teprenone has been reported to protect against ulcers induced by hydrochloric acid, aspirin, and ethanol, and to improve the poor proliferative capacity of gastric mucosal proliferation cells in hydrocortisone-induced ulcers (Arakawa et al. 1988; Murakami et al. 1982). It maintained the homeostasis of gastric mucosal proliferation cells to promote the healing of mucosal injury, and enhanced the biosynthesis of prostaglandin E2 in the gastric body and esophageal mucosa of normal rats. Teprenone 
promotes acetic acid-induced chronic gastric ulcer healing in rats (Kobayashi et al. 2001) and is now widely used clinically because of its low drug-drug interaction, unlike antacids containing metal ions (Saruta et al. 2010).

Teprenone is a mixture of $(5 E, 9 E, 13 E)$-geranylgeranylacetone (hereinafter referred to as "all-trans" form) and $(5 Z, 9 E, 13 E)$-geranylgeranylacetone (hereinafter referred to as "mono-cis" form). The APIs of teprenone should contain the mono-cis (Fig. 1A) and all-trans (Fig. 1B) forms at a ratio of approximately $2: 3$, and constitute $97.0-101.0 \%$ of teprenone.

Quantitation of teprenone is required for quality control of active pharmaceutical ingredients (APIs) and capsule preparation. In the pharmaceutical industry, quality control of teprenone has been performed by GC and HPLC according to the assay method in Japanese Pharmacopoeia (JP) 17th Edition. However, separation efficiency between teprenone isomers is poor in HPLC, and analysis time is too long in GC. Gas chromatography/hydrogen flame ionization detection (GC/FID) using packed silica-gel column and high-performance liquid chromatography/ultraviolet detection (HPLC/UV) using octadecylsilanized silica gel column have been applied for the assay of APIs and teprenone capsules, respectively (The Ministry of Health 2016).

Previously reported analytical studies for APIs and teprenone capsules were also based on the GC/FID (Guang 2009) or HPLC/UV (Xiao-jun 2007) methods described in the JP. The bioanalytical methods for human pharmacokinetics have been developed using highperformance liquid chromatography/fluorescence detection (HPLC/FLD) with fluorescent derivatization of teprenone (Seki et al. 1988), gas chromatography-mass spectrometry (GC-MS) (Tanaka et al. 1982), and liquid chromatography-mass spectrometry (LC-MS) (Ding et al. 2007).

However, these previous reported methods including JP methods using HPLC/UV were not able to completely separate the mono-cis and all-trans forms of teprenone. The reported method using GC/FID has a disadvantage of a long analysis time ( $20 \mathrm{~min})$ for separation of teprenone isomers. Therefore, it was not satisfactory as an analytical method used for quality control of teprenone APIs and capsules. To improve this, subcritical fluid chromatography (SubFC) and a porous graphitic carbon (PGC) column were introduced in our study. The combination of SubFC and PGC columns was expected to separate stereo isomers of teprenone effectively with good resolution within a short run time and showed good performance as expected. West et al. analyzed substituted aromatic isomers (o-, m-, p-xylene, etc.) with PGC column in SFC. In this paper, very similar positional isomers were separated within approximately 6 min (West and Lesellier 2005b). Gyllenhaal et al. separated selectively metoprolol from related amino alcohols using PGC column in SFC. This paper showed separation of closely structurally related substances (Gyllenhaal and Karlsson 2010).

In our study, mono-cis and all-trans forms of teprenone in capsules were separated by a SubFC/photo diode array detection (PDA) method using a PGC column to overcome and improve the disadvantages of the conventional LC and GC methods, and the quantitative analysis method of teprenone was developed and validated. SFC or SubFC has been a powerful analytical technique to separate the structural isomers within short run time that uses supercritical (or subcritical) fluid and is orthogonal to reversedphase chromatography. The most commonly used supercritical (or subcritical) fluid is $\mathrm{CO}_{2}$ and requires temperature and pressure conditions above those of the thermodynamic critical point as a phase, not as liquid or gas. The critical point of $\mathrm{CO}_{2}$ is at a temperature of $31{ }^{\circ} \mathrm{C}$ and pressure of 73.8 bar. The supercritical (or subcritical) fluid has properties intermediate between those of liquid and gas. It has lower viscosity than that of liquid and higher solubility and density than those of gas. Because of these properties, high flow rates can be applied, enabling fast and highly efficient analysis.

(A)<smiles>CC(=O)CC/C=C(/C)CC/C=C(\C)CC/C=C(\C)CCC=C(C)C</smiles>

(B)<smiles>CC(=O)CC/C=C(\C)CC/C=C(\C)CC/C=C(\C)CCC=C(C)C</smiles>

Fig. 1 Chemical structures of (A) mono-cis teprenone and (B) all-trans teprenone 
The PGC stationary phase used herein, which consists of hexagonal sheets of carbon atoms (Knox et al. 1986), has a different mechanism compared to the $\mathrm{C}_{18}$ stationary phase. Use of the PGC column increased retention of analytes, including aromatic compounds, by dispersion and strong $\pi-\pi$ interactions, and the analyte's electron-withdrawing or donating properties (Rinne et al. 2006; West and Lesellier 2005a; West and Lesellier 2005b). In addition, the PGC column is also known to be excellent for the separation of positional and structural isomers due to the unique surface properties of the graphitic carbon (Gundersen 2001). The planar surface of PGC contributes to the separation of structurally different analytes, and the edge of the graphite sheet is energetically homogeneous, which is also good for the separation of ionic compounds (Wan et al. 1995).

To the best of our knowledge, this is the first SubFCbased analytical method developed for separation of teprenone isomers. This method showed improved resolution between the teprenone isomers and reduced the analysis time compared to previous methods.

\section{Materials and methods}

\section{Chemicals and reagents}

The teprenone standard was provided by Hanseo Chemical Co. Ltd. (Pyeongtaek, Republic of Korea). HPLCgrade solvents (methanol, ethanol, isopropanol, and acetonitrile) were purchased from J\&W Honeywell (Phillipsburg, NJ, USA). Pressurized carbon dioxide gas (> 99.999\%) was provided by KS Tech Co., Ltd. (Anseong, Republic of Korea). Teprenone capsule $(50 \mathrm{mg} / \mathrm{capsule}$, With CapTM) was provided by Samjinpharm. Co. Ltd (Seoul, Republic of Korea).

\section{SubFC conditions}

The SubFC system used was equipped with a $\mathrm{CO}_{2}$ delivery unit (LC-30ADSF), a back-pressure control unit (SFC-30A), a modifier pump (LC-20ADXR), a column oven (CTO-20AC), and a photodiode array detector (SPD-M20A), all obtained from Shimadzu (Tokyo, Japan). The analytical column was Hypercarb PGC column $(100 \times 4.6 \mathrm{~mm}, 5 \mu \mathrm{m}$; Thermo Scientific, Waltham, MA, USA) and was maintained at $40{ }^{\circ} \mathrm{C}$. The mobile phase was composed of subcritical fluid $\mathrm{CO}_{2}$ and ethanol $(70 / 30, \mathrm{v} / \mathrm{v})$ at a $4.0 \mathrm{~mL} / \mathrm{min}$ flow rate. The injection volume was $10 \mu \mathrm{L}$, and the detection wavelength was $210 \mathrm{~nm}$. The back-pressure of the SubFC system was maintained at $10 \mathrm{MPa}$. The data acquisition program used the LabSolution (Ver. 5.91) software from Shimadzu.

\section{Preparation of standard solutions and samples}

The standard stock solution of teprenone was prepared at a concentration of $5 \mathrm{mg} / \mathrm{mL}$ by dissolving in ethanol.
The stock solution was diluted with ethanol to prepare working solutions of different concentrations (0.40, 0.45, $0.50,0.55$, and $0.60 \mathrm{mg} / \mathrm{mL}$ ) for constructing the calibration curve.

The capsule sample was prepared by weighing out the teprenone standard powder corresponding to one capsule and adding ethanol to obtain a volume of $100 \mathrm{~mL}$.

\section{Optimization of SubFC conditions}

For analysis of mono-cis and all-trans teprenone isomers with fast separation and high efficiency, the SubFC conditions, such as the type and content of organic modifier, column temperature, injection volume, and flow rate, were optimized.

The organic modifiers commonly used in SubFC are acetonitrile, methanol, ethanol, and isopropanol; thus, these solvents were compared. The content of the selected organic modifier was optimized by varying to $10,20,30$, 40 , and $50 \%$. In addition, because subcritical fluid is affected by temperature, the effect of column temperature was investigated by comparing temperatures of $35,40,45$, 50 , and $55^{\circ} \mathrm{C}$. Injection volumes of 5,10 , and $20 \mu \mathrm{L}$ and flow rate of $2,3,4$, and $5 \mathrm{~mL} / \mathrm{min}$ were compared.

The optimization experiment was performed with the teprenone standard working solution $(0.5 \mathrm{mg} / \mathrm{mL})$. The peak parameters for optimal SubFC conditions were evaluated in terms of capacity factor $\left(k^{\prime}\right)$, retention time $(\mathrm{RT})$, theoretical plate number $(\mathrm{N})$, tailing factor $\left(\mathrm{T}_{\mathrm{f}}\right)$, and resolution (Rs).

\section{Method validation}

The developed method was validated as per $\mathrm{ICH}$ guideline Q2(R1) in terms of accuracy, precision (repeatability and intermediate precision), specificity, linearity, quantification range, and robustness ( $\mathrm{ICH}$ 1994), along with stability.

\section{Specificity}

The specificity was confirmed by comparing the chromatograms of ethanol, excipient (placebo) of one blank capsule, and excipient spiked with teprenone isomers. The blank excipient and the excipient spiked with teprenone isomers were prepared by sample preparation method. We assessed whether interference appeared at the retention time of the teprenone isomers.

\section{Linearity and range}

The standard working solutions of teprenone isomers were prepared at different concentrations $(0.4,0.45,0.5$, 0.55 , and $0.6 \mathrm{mg} / \mathrm{mL}$ ) in ethanol by diluting the standard stock solution $(5 \mathrm{mg} / \mathrm{mL}$ in ethanol). These concentrations are $80-120 \%$ of the labeled amount of teprenone in drug preparation. The working solutions in the calibration curve were analyzed by repeating three times 
under the optimized SubFC condition, and calibration curves were constructed for the linearity test over the concentration range $0.4-0.6 \mathrm{mg} / \mathrm{mL}$.

\section{Accuracy}

Accuracy was evaluated in terms of recovery by addition of known quantities of the analyte to quantified drug product, according to the $\mathrm{ICH}$ guideline. Teprenone standard solutions equivalent to 5,10 , and $15 \%$ of QC sample $(0.5 \mathrm{mg} / \mathrm{mL})$ were added to quantified capsule samples. Three samples with added teprenone standard were prepared at each concentration and were quantified. Accuracy was calculated by comparing the theoretical and measured concentrations of teprenone isomers at each concentration.

\section{Precision}

In the ICH guideline, precision includes repeatability and intermediate precision. The repeatability test was performed by injecting six replicates at $0.5 \mathrm{mg} / \mathrm{mL}$ of standard solution, which was $100 \%$ concentration of the dosing preparation. We evaluated the repeatability by RSD of retention time and peak area of teprenone isomers.

The intermediate precision test was performed on both intra-day $(n=6)$ and inter-day $(n=3)$ basis. Intraday precision was evaluated as follows: one teprenone capsule was weighed precisely and dissolved in ethanol to a final volume of $100 \mathrm{~mL}$, from which six test solutions were prepared. The teprenone isomers were quantified using the linear calibration curve constructed by a developed method during a day. Inter-day precision was similarly assessed, with three test solutions over 3 days.

\section{Robustness}

In the ICH guideline, robustness is defined as the reliability of an analysis with respect to deliberate variations in method parameters. We verified that there is no significant effect on the analysis results, even when a slight change is made in the developed analytical method. The conditions of flow rate, organic modifier (ethanol) concentration in the mobile phase, and column oven temperature were changed by $\pm 10 \%$ from the optimized value for the evaluation of robustness. The applied conditions for robustness test were as follows: flow rate 3.6, 4.0, and 4.4 $\mathrm{mL} / \mathrm{min}$; organic modifier concentration 27,30 , and $33 \%$; column oven temperature 36,40 , and $44^{\circ} \mathrm{C}$.

\section{Stability}

Since the sample remains in solution for several hours in the laboratory prior to analysis, it is necessary to examine whether the stability of the sample solution is maintained in the laboratory environment during the time required for the test.
We evaluated the stability of the teprenone solution in a room temperature for $14 \mathrm{~h}$, by comparing the initial peak area of teprenone isomers and the post-elapsed peak area.

\section{Results and discussion \\ Optimization of SubFC conditions Selection of organic modifier}

The type and content of the organic modifier in the mobile phase influence the retention time, resolution, and selectivity of the analytes in SubFC. The subcritical fluid $\mathrm{CO}_{2}$ and the organic modifier act as non-polar and polar solvents, respectively, in SubFC.

Acetonitrile, methanol, ethanol, and isopropanol were tested as organic modifiers for teprenone analysis. A 50/ $50(\mathrm{v} / \mathrm{v})$ ratio of $\mathrm{CO}_{2}$ to organic modifier in the mobile phase was applied for the selection test. The other conditions (column temperature, injection volume, and flow rate) of the SubFC system were maintained at $40{ }^{\circ} \mathrm{C}, 5$ $\mu \mathrm{L}$, and $3 \mathrm{~mL} / \mathrm{min}$, respectively.

The organic modifiers were evaluated in terms of resolution, retention time (capacity factor), theoretical plate number, and tailing factor. These results are plotted as a radar chart (Fig. 2), in which the best value of each peak parameter was set at $100 \%$ and the rest of the values were expressed as percentages. The ideal value of each peak parameter was that which gave the highest resolution and theoretical plate number, and the lowest capacity factor and tailing factor.

The ascending order of retention time for the last analyte peak was as follows: isopropanol, ethanol, acetonitrile, and methanol. Relatively non-polar solvents, i.e., isopropanol and ethanol, showed fast elution of teprenone, while methanol showed the slowest elution. For methanol, the resolution between cis- and transteprenone was the best (Rs: 7.3), but the retention time of teprenone was too long (RT: cis, $21.8 \mathrm{~min}$; trans, 32.7 min). Considering the influence of background noise at low wavelength $(210 \mathrm{~nm})$, acetonitrile was a suitable organic modifier. However, ethanol gave short analysis run time (RT: cis, $3.6 \mathrm{~min}$; trans, $5.1 \mathrm{~min}$ ) and good tailing factor $\left(\mathrm{T}_{\mathrm{f}}\right.$ : cis, 1.14; trans, 1.26), along with reasonable resolution (Rs 5.5), compared to acetonitrile. In addition, ethanol is the most environment-friendly solvent, having the lowest toxicity among the four solvents. Thus, ethanol was selected as the organic modifier. The chromatograms for the organic modifier test are shown in Fig. 3A.

\section{Optimization of organic modifier content in mobile phase}

The elution in SFC (or SubFC) works like normal-phase chromatography. The organic modifier acts as a polar solvent in the SFC (or SubFC) system. The higher the content of the organic modifier, the faster the elution is obtained from the SFC (or SubFC). The modifiers were 


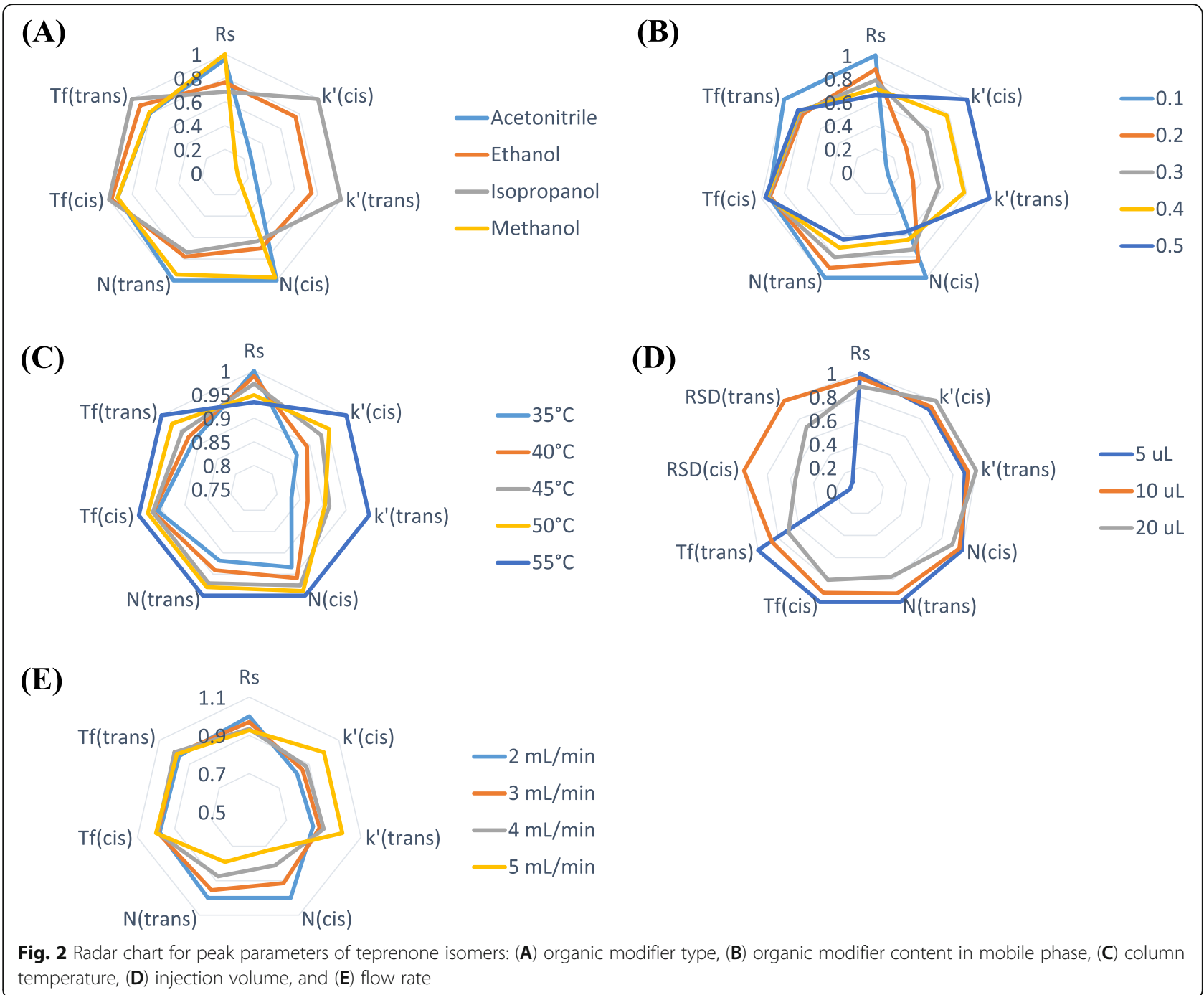

added to shorten analysis time, reduce peak tailing, and improve peak resolution, but it is true that the presence of a modifier increases the critical point. That is, higher temperatures and/or pressures are required to have a $\mathrm{CO}_{2}$-based mobile phase in the supercritical stage. However, due to the continuum of properties when moving from the supercritical to the subcritical phase, temperature and pressure conditions can be kept constant throughout the experiment. The difference between supercritical and subcritical condition is whether the temperature and pressure of the mobile phase have reached the critical point.

In this study, the content of ethanol was adjusted to shorten the retention time as much as possible at an appropriate resolution. For this reason, it was carried out under subcritical conditions, not supercritical conditions due to the high content of ethanol. If the organic modifier content is too high, $\mathrm{CO}_{2}$ can be worked as subcritical fluid and the system pressure may become unstable.
The effect of ethanol content was evaluated by varying the content to $10,20,30,40$, and $50 \%$. The other conditions were kept constant, as in the selection of organic modifier (column temperature, $40{ }^{\circ} \mathrm{C}$; injection volume, $5 \mu \mathrm{L}$; flow rate, $3 \mathrm{~mL} / \mathrm{min}$ ).

With increasing ethanol content, capacity factor $\left(k^{\prime}\right)$, resolution (Rs), and theoretical plate number $(\mathrm{N})$ were found to decrease. The tailing factor $\left(\mathrm{T}_{\mathrm{f}}\right)$ showed no remarkable change, except that of trans-teprenone at $10 \%$ ethanol content (Fig. 2B). The decrease in theoretical plate number with increasing ethanol content is attributed to the subcritical fluid gradually becoming liquidlike with increasing viscosity. In the radar chart, the Rs and $\mathrm{N}$ values were inversely related to the capacity factor when the type and content of organic modifier and the flow rate were compared (Fig. 2A, B, E). Finally, ethanol content of $30 \%$ was chosen, at which the subcritical fluid was stable and reasonable Rs and $\mathrm{N}$ values were obtained for teprenone isomers, along with separation 


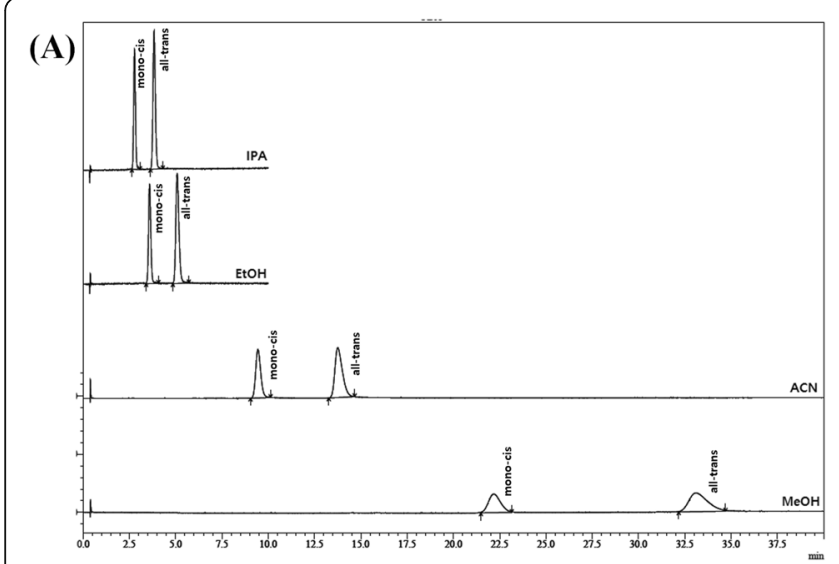

(B)

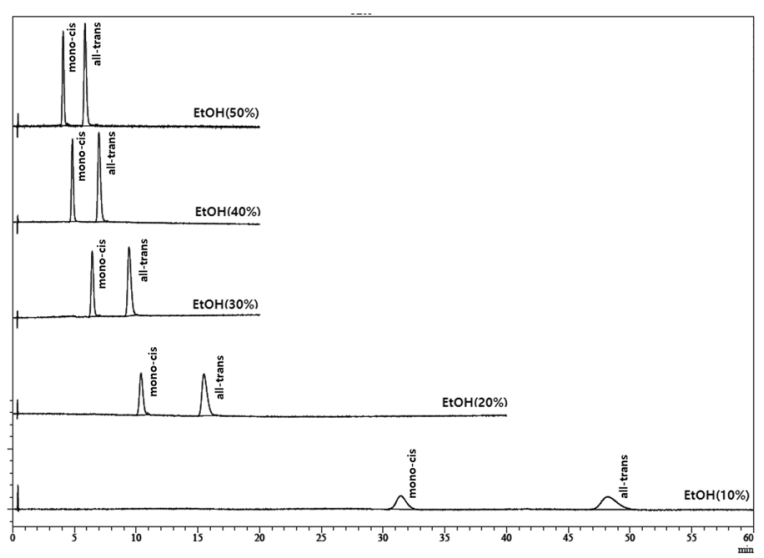

(C)

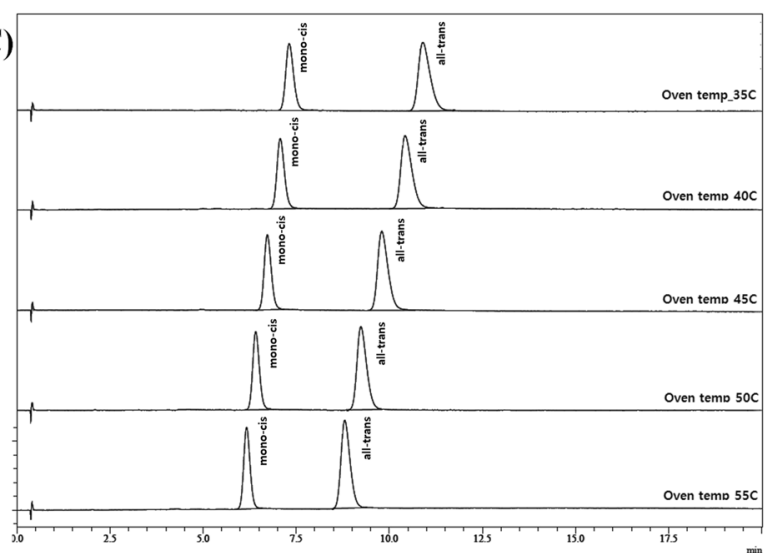

(E)

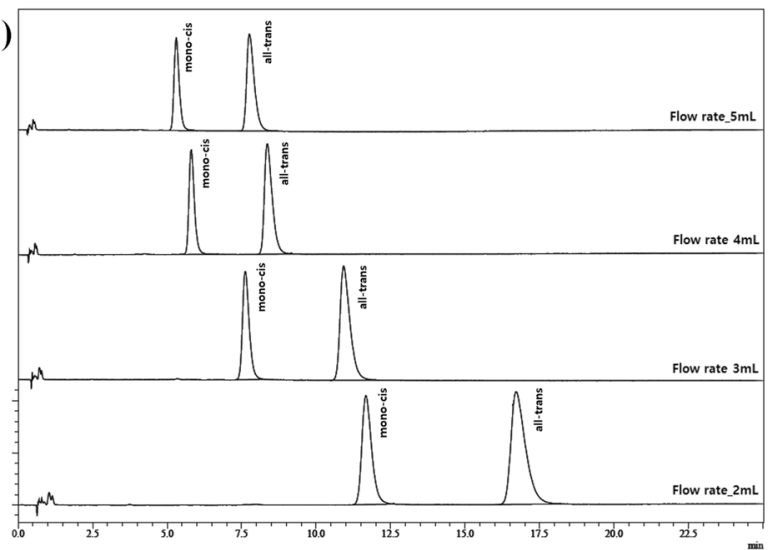

(D)

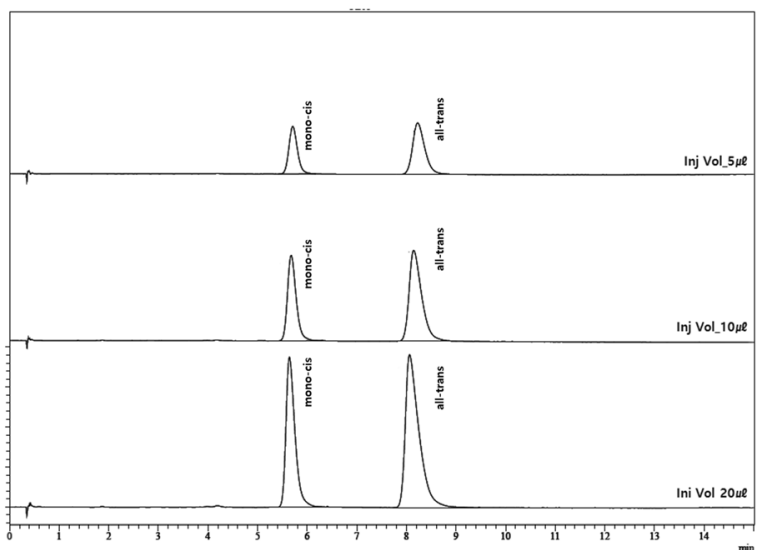

Fig. 3 SubFC/PDA chromatograms obtained during the optimization of chromatographic conditions: (A) organic modifier type, (B) organic modifier content in mobile phase, (C) column temperature, (D) injection volume, and (E) flow rate

within $10 \mathrm{~min}$. The chromatograms of the organic modifier content test are shown in Fig. 3B.

\section{Optimization of column temperature}

Different column temperatures $\left(35,40,45,50\right.$, and $\left.55^{\circ} \mathrm{C}\right)$ were tested by applying $30 \%$ ethanol as the optimized organic modifier. The injection volume and flow rate were maintained at $5 \mu \mathrm{L}$ and $3 \mathrm{~mL} / \mathrm{min}$, respectively.
The experimental results showed that with increasing column temperature, the peak parameters were improved, except resolution, unlike the other SubFC conditions. However, there were no remarkable differences in peak parameters at different column temperatures. In the radar chart, the range of peak parameters was 75$100 \%$ (Fig. 2C). The selected column temperature was $40{ }^{\circ} \mathrm{C}$ in consideration of resolution and deterioration of 
column at high temperature. The chromatograms for the column temperature test are shown in Fig. 3C.

\section{Optimization of injection volume}

The injection volume affects the sensitivity and reproducibility of the peaks. The peak parameters and repeatability of peak area were evaluated at different injection volumes. In the radar chart, the repeatability (relative standard deviation (RSD)) of trans- and cis-teprenone was added. The injection volumes of 5,10 , and $20 \mu \mathrm{L}$ were compared by applying $30 \%$ ethanol as the optimized organic modifier. The column temperature and flow rate were maintained at $40{ }^{\circ} \mathrm{C}$ and $4 \mathrm{~mL} / \mathrm{min}$, respectively.

With decreasing injection volume, $\mathrm{N}$, Rs, and $\mathrm{T}_{\mathrm{f}}$ values of teprenone isomers were improved. The standard working solutions of teprenone isomers were analyzed six times to evaluate the repeatability of the peak area; the RSD of the peak area was remarkably different according to the injection volume. The best reproducible peak area was obtained for an injection volume of $10 \mu \mathrm{L}$ (Fig. 2D); therefore, $10 \mu \mathrm{L}$ was selected as the injection volume due to appropriate resolution and reproducibility. The chromatograms for the injection volume test are shown in Fig. 3D.

\section{Optimization of flow rate}

Different flow rates of the mobile phase $(2,3,4$, and 5 $\mathrm{mL} / \mathrm{min}$ ) were compared with $30 \%$ ethanol. The teprenone working solution was analyzed with three times repetition at a column temperature of $40{ }^{\circ} \mathrm{C}$ and an injection volume of $10 \mu \mathrm{L}$. With increasing flow rate, capacity factor was improved, and resolution and theoretical plate number were decreased. No remarkable difference in tailing factor was observed for different flow rates. The selected flow rate was $4 \mathrm{~mL} / \mathrm{min}$, considering run time within $10 \mathrm{~min}$ and appropriate peak parameters. The chromatograms for the flow rate test are shown in Fig. 3E.

\section{Method validation Specificity}

The excipient of one capsule (blank) and the excipient spiked with $50 \mathrm{mg}$ teprenone standard were dissolved in $100 \mathrm{~mL}$ of ethanol and analyzed to evaluate the specificity of the method. The excipients in teprenone capsule are composed of cornstarch, lactose hydrate, polyethylene glycol 6000, talc, silicon dioxide, and dl- $\alpha$-tocopherol. Most of the excipient components did not have chromophore. We confirmed that no interference was present at the retention time of teprenone isomers in the chromatograms of ethanol and excipient (blank). The chromatograms for specificity are shown in Fig. 4A-C.

The expected elution order was confirmed through the contents of the Japanese and Korean Pharmacopoeia and the previous GC and LC analytical results. That is, as explained in the Japanese Pharmacopoeia (17th Edition) and the Korean Pharmacopoeia (12th Edition), "Teprenone is comprised of mono-cis and all-trans isomer, with their ratio being about 2:3". Even in the numerous analysis results in our study, the isomer area ratio was always $2 / 3$ for the early retention time peak (mono-cis)/ the late retention time peak (all-trans). This was the same as the elution order in HPLC or GC.

\section{Linearity and range}

The teprenone standard working solutions were prepared at concentrations of $80-120 \%(0.4-0.6 \mathrm{mg} / \mathrm{mL})$ in pharmaceutical preparation and were analyzed three times. The correlation coefficient $\left(\mathrm{r}^{2}\right)$ exceeded 0.999 at the calibration range $0.4-0.6 \mathrm{mg} / \mathrm{mL}$, which indicated favorable linearity. The precision $(n=3)$ of the calibration curve slope was within $0.5 \%$ as the relative standard deviation (RSD, \%).

\section{Accuracy}

Accuracy was evaluated in terms of recovery by addition of teprenone standard equivalent to 5,10 , and $15 \%$ of QC sample $(0.5 \mathrm{mg} / \mathrm{mL})$ to the quantified drug product. The average recovery was $99.94-100.39 \%$, and RSD was $0.5-0.8 \%$. These results of recovery close to $100 \%$ and RSD of less than $1 \%$ prove that the developed method was accurate (Table 1 ).

\section{Precision}

The repeatability test was performed by analyzing six replicates at $0.5 \mathrm{mg} / \mathrm{mL}$ of standard solution and evaluated in terms of RSD of retention time and peak area. The RSD of retention time and peak area was 0.07$0.10 \%$ and $0.35-0.55 \%$, respectively. Thus, the peaks of cis- and trans-teprenone showed good repeatability of the retention time and peak area.

The intermediate precision test was evaluated by assay results on intra- $(n=6)$ and inter-day $(n=3)$. The results of intra- and inter-day precision test showed RSD of $0.4 \%$ and $0.3-1.4 \%$, respectively. These RSD values of approximately $1 \%$ or less confirmed the precision of the developed method and the SubFC system (Table 2).

\section{Limit of quantitation (LOQ) and limit of detection (LOD)}

The calibration curve samples were analyzed three times for calculation of the LOQ and LOD. The LOQ and LOD were calculated by the following equation. $\sigma$ is the standard deviation of intercept. $S$ is the mean value of slope.

$$
\mathrm{LOQ}=10 \times \sigma / S ; \mathrm{LOD}=3.3 \times \sigma / S
$$

In this developed method, the LOQ and LOD were 25.8 and $8.5 \mu \mathrm{g} / \mathrm{mL}$, respectively. In the previous reports, 


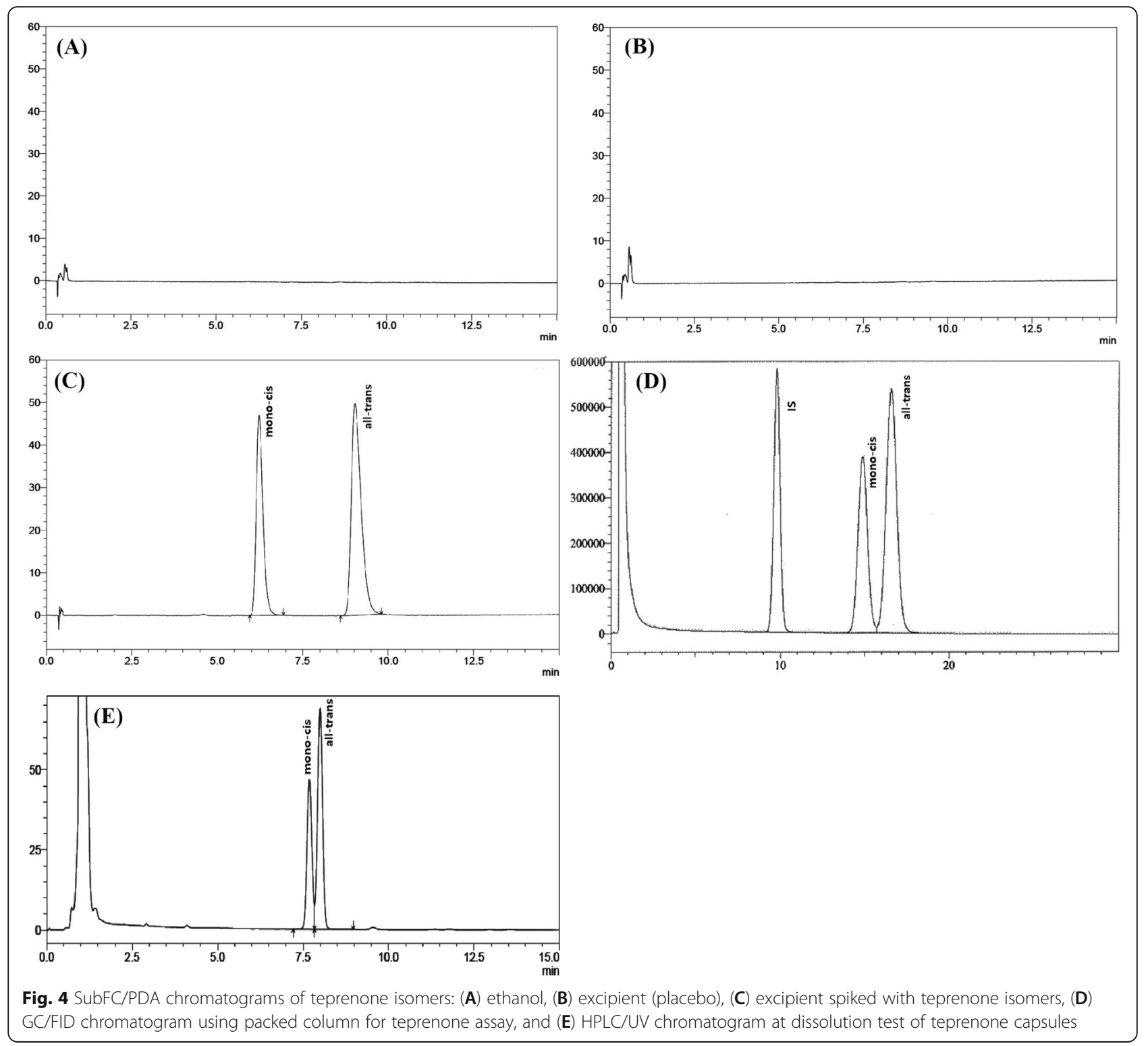

the LOQ of teprenone was $100 \mu \mathrm{g} / \mathrm{mL}$ by GC/FID (Guang 2009) and $0.05 \mu \mathrm{g} / \mathrm{mL}$ by HPLC/UV (Xiao-jun 2007). Although the LOQ $(25.8 \mu \mathrm{g} / \mathrm{mL})$ in this method is lower than that of the HPLC/UV method (Xiao-jun 2007), it is considered to be sufficient to measure the nominal concentration of $500 \mu \mathrm{g} / \mathrm{mL}$ in the teprenone capsule. In addition, it is not clear whether mono-cis and all-trans forms were completely separated in the previously reported HPLC/UV method (Xiao-jun 2007).

\section{Robustness}

The robustness test was performed by varying flow rate, content of organic modifier in mobile phase, and column oven temperature by $\pm 10 \%$ from optimized value. The applied conditions were as follows: flow rates 3.6, 4.0, and $4.4 \mathrm{~mL} / \mathrm{min}$; organic modifier contents 27,30 , and
$33 \%$; column oven temperatures 36,40 , and $44{ }^{\circ} \mathrm{C}$. The $\mathrm{N}, \mathrm{T}_{\mathrm{f}}$, and Rs of cis- and trans-teprenone were evaluated by varying these analytical conditions; no remarkable differences in peak parameters were observed. Thus, teprenone isomers were analyzed with a good peak shape and resolution. The RSDs of the $\mathrm{N}, \mathrm{T}_{\mathrm{f}}$, and Rs values were $2.8-4.6 \%, 0.2-2.2 \%$, and $0.2-2.6 \%$, respectively.

\section{Stability}

The prepared solution stability of teprenone isomers was evaluated at room temperature for $14 \mathrm{~h}$ during analysis. There was almost no difference between the initial peak area of teprenone isomers and the post-elapsed peak area, with an RSD of $0.33-0.60 \%$. This confirms that the teprenone solution was stable during analysis. 
Table 1 Accuracy determination by method validation $(n=3)$

\begin{tabular}{|c|c|c|c|c|c|}
\hline \multirow{2}{*}{$\begin{array}{l}\text { Added } \\
\text { conc. } \\
\text { ratio }\end{array}$} & \multirow{2}{*}{$\begin{array}{l}\text { Measured } \\
\text { conc. in } \\
\text { capsule } \\
(\mu \mathrm{g} / \mathrm{mL})\end{array}$} & \multirow{2}{*}{$\begin{array}{l}\text { Added } \\
\text { conc. } \\
(\mu \mathrm{g} / \\
\mathrm{mL})\end{array}$} & \multirow{2}{*}{$\begin{array}{l}\text { Measured } \\
\text { total conc. } \\
(\mu \mathrm{g} / \mathrm{mL})\end{array}$} & \multicolumn{2}{|l|}{ Recovery } \\
\hline & & & & Mean (\%) $\left(95 \% \mathrm{Cl}^{*}\right)$ & RSD (\%) \\
\hline \multirow[t]{3}{*}{$5 \%$} & 495.8 & 24.4 & 524.4 & $100.1 \pm 0.7$ & 0.7 \\
\hline & 495.6 & & 519.5 & & \\
\hline & 499.0 & & 520.9 & & \\
\hline \multirow[t]{3}{*}{$10 \%$} & 495.8 & 48.8 & 543.0 & $99.9 \pm 0.6$ & 0.5 \\
\hline & 495.6 & & 547.3 & & \\
\hline & 499.0 & & 545.6 & & \\
\hline \multirow[t]{3}{*}{$15 \%$} & 495.8 & 73.2 & 575.0 & $100.4 \pm 0.9$ & 0.8 \\
\hline & 495.6 & & 572.4 & & \\
\hline & 499.0 & & 569.4 & & \\
\hline
\end{tabular}

${ }^{*} \mathrm{Cl}$ confidence interval

\section{Comparison of SubFC/PDA, HPLC/UV, and GC/FID}

The API of teprenone was analyzed by the GC/FID and HPLC/UV methods (described in the JP) for comparing the SubFC/PDA, HPLC/UV, and GC/FID methods. In the JP methods, a glass column with an inside diameter of 3 $\mathrm{mm}$ and length of $2 \mathrm{~m}$, packed with 149-177 $\mu \mathrm{m}$ silica-gel coated in 5\% with polyethylene glycol 2-nitroterephthalate is used for gas chromatography. Herein, Uniport HP 80/ 100 mesh (4 mm I.D. $\times 2.1 \mathrm{~m}$; 5\% FFAP) column was used. The GC/FID method using the packed column for the JP methods required a long run time of $\sim 20 \mathrm{~min}$ to separate the teprenone isomers. In HPLC/UV method in the JP, a stainless-steel column $4.6 \mathrm{~mm}$ in inside diameter and $15 \mathrm{~cm}$ in length, packed with octadecylsilanized silica gel ( $5 \mu \mathrm{m}$ of particle size) is used. Herein, ACE5 $\mathrm{C}_{18}$ column (4.6 mm I.D. $\times 150 \mathrm{~mm}, 5 \mu \mathrm{m})$ with $40^{\circ} \mathrm{C}$ of column temperature was used. The mobile phase was a mixture of acetonitrile and water $(87 / 13, \mathrm{v} / \mathrm{v})$ as in the JP with 1.6 $\mathrm{mL} / \mathrm{min}$ of flow rate.

In the GC/FID method, the resolution between the cis- and trans-teprenone was approximately 1.5 , indicating narrow separation (Fig. 4D). In the assay using the HPLC/UV method described in the JP, the teprenone isomers were slightly separated within $10 \mathrm{~min}$, but there was no baseline separation (Fig. 4E).

The SubFC/PDA method developed herein had a resolution of 6.3 for teprenone isomers within $10 \mathrm{~min}$ of run time (Fig. 4C), which is improved compared to those of
GC/FID or HPLC/UV method. In addition, di-n-butyl phthalate, used as the internal standard in the JP methods, is an endocrine disruptor, which can be dangerous to researchers. However, the SubFC/PDA method showed excellent accuracy and precision in method validation, even though no internal standard was used.

Although SFC (or SubFC) has disadvantages in cost and complexity compared to HPLC, it is worthwhile as it has a different separation mechanism and orthogonality than HPLC and GC. The initial price of SFC (or SubFC) equipment is rather expensive; however, it has obvious advantages in terms of maintenance costs (solvent price) and environmental aspects. In addition, it is very beneficial to the safety of analytical researchers as it uses only $\mathrm{CO}_{2}$ and ethanol, without the use of harmful organic solvents for the preparation of standards and samples, and analysis procedures.

\section{Conclusion}

A very fast and highly selective SubFC/PDA method was developed and validated for the separation of mono-cis and all-trans teprenone isomers in pharmaceutical preparation. The separation of teprenone isomers was performed on a porous graphitic carbon column. The SubFC conditions were evaluated and optimized for high-efficiency analysis. The SubFC parameters were optimized for the type and content of organic modifier, column temperature, injection volume, and flow rate,

Table 2 Intermediate precision by method validation

\begin{tabular}{llllll}
\hline Validation & & Concentration $(\boldsymbol{\mu} \mathbf{g} / \mathbf{m L})$ & Measured conc. $(\boldsymbol{\mu g} / \mathbf{m L})(\mathbf{9 5} \% \mathbf{C l}$ ) & Precision $(\mathbf{R S D}, \mathbf{\%})$ & $\mathbf{A c c u r a c y}(\%)(\mathbf{9 5} \% \mathbf{C l})$ \\
\hline Intra-day $(n=6)$ & & 500.0 & $494.8 \pm 1.5$ & 0.4 & $99.0 \pm 0.3$ \\
Inter-day $(n=3)$ & Day 1 & 500.0 & $495.7 \pm 3.4$ & 0.6 & $99.1 \pm 0.6$ \\
& Day 2 & 500.0 & $496.5 \pm 1.8$ & 0.3 & $99.2 \pm 0.3$ \\
& Day 3 & 500.0 & $494.7 \pm 7.7$ & 1.4 & $98.9 \pm 1.5$ \\
\hline
\end{tabular}


which were ethanol, $30 \%, 40{ }^{\circ} \mathrm{C}, 10 \mu \mathrm{L}$, and $4 \mathrm{~mL} / \mathrm{min}$, respectively.

These parameters were evaluated using the peak parameters of teprenone isomers, such as capacity factor $\left(k^{\prime}\right)$, retention time $(\mathrm{RT})$, theoretical plate number $(\mathrm{N})$, tailing factor $\left(\mathrm{T}_{\mathrm{f}}\right)$, and resolution (Rs). The developed method was validated in terms of accuracy, precision (repeatability and intermediate precision), specificity, linearity, range, and robustness, according to $\mathrm{ICH}$ guideline Q2(R1). In addition, the stability of teprenone was evaluated during $14 \mathrm{~h}$ at room temperature. When the SubFC/PDA method described herein and the GC/FID or HPLC/UV methods described in the JP were compared, the SubFC/PDA method showed improved resolution of teprenone isomers and shortened run time.

Although a large number of actual teprenone capsules were not analyzed in this study, it is considered that it can be sufficiently applied to quality control of actual products through method validation. In addition, the developed SubFC/PDA analysis method is expected to be reflected in the official compendium and applied to the industrial site.

\section{Acknowledgements}

Not applicable.

\section{Authors' contributions}

CHJ: conceptualization, validation, formal analysis, investigation, resources, data curation, writing - original draft preparation. HYE: resources, visualization, writing - original draft. SJB: validation, formal analysis, data curation. HDC: investigation, writing-original draft. SBH: conceptualization, supervision, project administration. The authors read and approved the final manuscript.

\section{Funding}

Not applicable.

Availability of data and materials

Not applicable.

\section{Declarations}

\section{Competing interests}

The authors declare that they have no competing interests.

\section{Author details}

'Department of Pharmaceutical Analysis, College of Pharmacy, Chung-Ang University, 84 Heukseok-ro, Dongjak-gu, Seoul 06974, Republic of Korea. ${ }^{2}$ Samjinpharm Co., LTD., 121 Wausan-ro, Mapo-gu, Seoul 04054, Republic of Korea. ${ }^{3}$ Bioanalytical and Pharmacokinetic Study Group, Korea Institute of Toxicology, 141 Gajeong-ro, Yuseong-gu, Daejeon 34114, Republic of Korea.

Received: 5 May 2021 Accepted: 14 June 2021

Published online: 28 June 2021

\section{References}

Arakawa T, Yamada H, Nakamura A, Nebiki H, Satoh H, Fukuda T, et al. Gastric cytoprotection by tetraprenylacetone in human subjects. Digestion. 1988; 39(2):111-7. https://doi.org/10.1159/000199613.

Ding L, Zhu T, Song Q, Zhang Y, Shen J. HPLC-APCI-MS for the determination of teprenone in human plasma: method and clinical application. J Pharm Biomed Anal. 2007;44(3):779-85. https://doi.org/10.1016/j.jpba.2007.03.021.

Guang F. GC determination of terprenone capsules. Chin J Pharm Anal. 2009:29: 998-1000.
Gundersen JL. Separation of isomers of nonylphenol and select nonylphenol polyethoxylates by high-performance liquid chromatography on a graphitic carbon column. J Chromatogr A. 2001;914(1):161-6. https://doi.org/10.1016/ S0021-9673(00)01235-8.

Gyllenhaal O, Karlsson A. Evaluation conditions for SFC of metoprolol and related amino alcohols on hypercarb (porous graphitic carbon) with respect to structure-selectivity relations. Chromatographia. 2010;71(1):7-13. https://doi. org/10.1365/s10337-009-1406-3.

ICH Harmonised Tripartite Guideline (1994) Validation of analytical procedures: text and methodology Q2(R1).

Knox JH, Kaur B, Millward GR. Structure and performance of porous graphitic carbon in liquid chromatography. J Chromatogr A. 1986;352:3-25. https://doi. org/10.1016/S0021-9673(01)83368-9.

Kobayashi T, Ohta Y, Yoshino J, Nakazawa S. Teprenone promotes the healing of acetic acid-induced chronic gastric ulcers in rats by inhibiting neutrophil infiltration and lipid peroxidation in ulcerated gastric tissues. Pharmacol Res. 2001;43(1):23-30. https://doi.org/10.1006/phrs.2000.0748.

Murakami M, Oketani K, Fujisaki H, Wakabayashi T, Ohgo T. Antiulcer effect of geranylgeranylacetone, a new acyclic polyisoprenoid on experimentally induced gastric and duodenal ulcers in rats. Arzneimittelforschung. 1981; 31(5):799-804.

Murakami M, Oketani K, Fujisaki H, Wakabayashi T, Ohgo T, Okabe S. Effects of the antiulcer drug geranylgeranylacetone on aspirin-induced gastric ulcers in rats. Jpn J Pharmacol. 1982;32(2):299-306. https://doi.org/10.1016/S0021-51 98(19)52695-6.

Rinne S, Holm A, Lundanes E, Greibrokk T. Limitations of porous graphitic carbon as stationary phase material in the determination of catecholamines. J Chromatogr A. 2006;1119(1):285-93. https://doi.org/10.1016/j.chroma.2006.03.003.

Saruta N, Fukami T, Furuishi T, Suzuki T, Tomono K. Powdered formulation of liquid oil terpenoid included in cyclodextrins for chemical stabilization and improved handling. Adv Powder Technol. 2010;21(3):326-30. https://doi.org/1 0.1016/j.apt.2009.12.016.

Seki T, Hashida N, Kanazawa T. Determination of tetraprenylacetone in human plasma by high-performance liquid chromatography with fluorescence derivatization using dansylhydrazine. J Chromatogr B Biomed Sci Appl. 1988; 424:410-5. https://doi.org/10.1016/50378-4347(00)81121-4.

Tanaka M, Hasegawa J, Tsutsumi J, Fujita T. Determination of the anti-ulcer agent geranylgeranylacetone in serum by gas chromatography-mass spectrometry. J Chromatogr B Biomed Sci Appl. 1982;231 (2):301-10. https://doi.org/10.101 6/50378-4347(00)81855-1.

The Ministry of Health, Labour and Welfare (2016) The Japanese Pharmacopoeia Seventeenth Edition.

Wan QH, Shaw PN, Davies MC, Barrett DA. Chromatographic behaviour of positional isomers on porous graphitic carbon. J Chromatogr A. 1995;697(1): 219-27. https://doi.org/10.1016/0021-9673(94)00813-O.

West C, Lesellier E. Effects of modifiers in subcritical fluid chromatography on retention with porous graphitic carbon. J Chromatogr A. 2005a;1087(1):6476. https://doi.org/10.1016/j.chroma.2005.03.104.

West C, Lesellier E. Separation of substituted aromatic isomers with porous graphitic carbon in subcritical fluid chromatography. J Chromatogr A. 2005b; 1099(1):175-84. https://doi.org/10.1016/j.chroma.2005.09.002.

Xiao-jun C. Determination of terprenone in soft capsules. Hebei Chem Eng Ind. 2007;3:60-

\section{Publisher's Note}

Springer Nature remains neutral with regard to jurisdictional claims in published maps and institutional affiliations. 